\title{
Genotoxicidad del agua contaminada por plaguicidas en un área de Antioquia
}

\section{Genotoxicity of water contaminated by plaquicidas in an area of Antioquia}

\author{
Flor Tobón M, ${ }^{1 *}$ M.Sc, Luís López G, ${ }^{1}$ M.Sc. \\ ${ }^{1}$ Universidad de Antioquia. Facultad de Química Farmacéutica y Facultad de Enfermería, Grupo de \\ Investigación UNI-PLURI/VERSIDAD, Medellín, Colombia. *Correspondencia: jvm@une.net.co
}

Recibido: Junio de 2010; Aceptado: Enero de 2011.

\section{RESUMEN}

Objetivo. Determinar genotoxicidad del extracto orgánico de recursos hídricos de la vereda Monterredondo (Antioquia), contaminados por el uso de pesticidas en la agricultura, en la producción porcina y avícola como un diagnóstico de su calidad para entender su influencia en estas fuentes de agua en el municipio de San Pedro de Los Milagros (Antioquia). Materiales y métodos. Se empleó el ensayo cometa para establecer fragilidad osmótica de eritrocitos, viabilidad celular y alteración del ADN de linfocitos humanos al incubar estas células en agua recogida de tres fuentes hídricas de la vereda Monterredondo en el laboratorio de Bioquímica de la Facultad de Medicina de la Universidad de Antioquia. Resultados. El análisis de los datos de la longitud del cometa del extracto orgánico de las tres muestras, indicaron genotoxicidad. Este efecto fue dependiente de la concentración del extracto y del sitio de muestreo $(p<0.001)$. La muestra de agua de la quebrada el Hato, presentó el mayor efecto genotóxico a 4 y $37^{\circ} \mathrm{C}$; la muestra de agua de la planta de tratamiento de la Hacienda La Montaña, presentó una alta genotoxicidad relativa, comparada con la muestra de agua de la quebrada Fray Juana. Conclusiones. El análisis de las tres muestras de agua recogidas en la vereda Monterredondo reveló genotoxicidad. Sin embargo, se sugiere en el futuro evaluar el grado de toxicidad de los componentes orgánicos concentrados y la genotoxicidad en personas que la consumen.

Palabras clave: Agua, extracto orgánico, genotoxicidad, ensayo cometa, contaminación ambiental, Colombia. (Fuentes: AIMS, CAB). 


\section{ABSTRACT}

Objective. Determining genotoxicity of organic extract from water resources contaminated by the pesticides used in agriculture, pig and poultry production in Monterredondo village (Antioquia), as a diagnosis of its quality to understand its influence on these water sources in San Pedro de Los Milagros (Antioquia). Materials and methods. Comet assay was used to establish osmotic fragility of erythrocytes, cell viability and DNA damage in human lymphocytes by incubating of these cells in three samples of water collected from sources in the village of Monterredondo in the laboratory of Biochemistry, Faculty of Medicine of the University Antioquia. Results. Data analysis of the comet's assay length of the organic extract from the three collected samples, indicates genotoxicity. This effect is dependent on the concentration of the extract and the sampling site $(p<0.001)$. The sample of water from the Hato River shows the highest genotoxic effect at 4 and $37^{\circ} \mathrm{C}$. The water sample, from treatment plant Hacienda La Montaña shows relative high genotoxicity, compared to the sample water taken from Fray Juana river. Conclusions. The analysis of the three water samples, collected in the Monterredondo village, reveals genotoxicity. However, further evaluation on the toxicity grade of the concentrated organic components and the genotoxicity in people who drink it, is suggested.

Key words: Water, organic extract, genotoxicity, comet assay, environmental contamination, Colombia. (Sources: AIMS, CAB)

\section{INTRODUCCIÓN}

Las actividades agropecuarias y los residuos de alimentos, entre otros; generan desperdicios tóxicos y sus vertimientos a fuentes hídricas ingresan en un ecosistema a una velocidad que excede la capacidad normal de éste para procesarlos y distribuirlos, constituyéndose en un problema de contaminación ambiental. Una forma de contribuir a prever y evitar este problema esencial, que es la determinación de genotoxicidad producida por vertimientos de algunos productos químicos en las fuentes hídricas que pueden desencadenar mutaciones, alterando los códigos en la secuencia del ácido desoxirribonucleico (ADN).

Se entiende la genotoxicidad como la acción deletérea de un agente o sustancia que interactúa de una forma directa o indirecta con el ADN, modificándolo y afectando su integridad. El efecto genotóxico del agente o sustancia sobre el ADN genera cambio errático permanente (mutación) en el genotipo de determinada célula en el proceso de división celular, pudiendo producir o no un cáncer. Aunque, existen aspectos por aclarar en la relación compleja entre la exposición a un genotóxico y el desarrollo de cáncer que puede ser o no cancerígeno. En el caso de ser cancerígeno, éste tiene una alta probabilidad de ser genotóxico (1).

La contaminación resulta de la aplicación directa sobres bovinos, porcinos, aves y cultivos; además de otras sustancias provenientes de contribuciones de residuos que llegan a los afluentes por las aguas negras y de la atmósfera por lixiviación, escorrentía y precipitación. De acuerdo a publicaciones sobre genotoxicidad de estas sustancias químicas se ha determinado en diferentes especies, in vitro e in vivo; las relacion con la utilización indiscriminada de pesticidas y plaguicidas, también se asocian con la posibilidad de desencadenar mutaciones por la exposición crónica a dosis pequeñas en actividades ocupacionales o por circunstancias accidentales que en ocasiones inician un proceso carcinogénico $(3,4)$. El uso del Glifosato, un herbicida total, no selectivo de amplio espectro, es un factor de riesgo para la salud y puede afectar el ADN en cientos de células en concentraciones normales en el agua potable; pero se requiere evaluar sus 
efectos, tales como el tipo de cáncer y el período en que se convierte en un riesgo potencial para los seres humanos $(2,5-7)$.

Esta investigación, buscó ampliar el conocimiento de la problemática ambiental y contribuir a su contención mediante la evaluación de la genotoxicidad de las dos muestras de agua sin tratar y la muestra de agua tratada para que de una manera progresiva con fundamentos científicos, incentivar acciones hacia una disminución del uso indiscriminado de pesticidas y herbicidas, una preocupación global, por su alta toxicidad y consecuencia de sus efectos en la calidad del agua y la repercusión en la salud de la población.

En este sentido, la agricultura basada en prácticas no apropiadas dependientes de plaguicidas (insecticidas, herbicidas, fungicidas) y fertilizantes tóxicos, es apoyada y promovida en Colombia por políticas nacionales e internacionales, desde la década de 1950. Dichas prácticas contaminan los ecosistemas acuáticos y terrestres, y los alimentos; causando graves problemas de salud a corto, mediano y largo plazo. Dichas prácticas inadecuadas contaminan las fuentes hídricas, alterando la biodiversidad de flora y fauna, desarrollando resistencia de plagas y aparición de enfermedades. Esto hace más costosa la agricultura, más pobres y enfermos a los agricultores; además de un impacto negativo a los ecosistemas (8-10).

El objetivo de esta investigación fue determinar genotoxicidad del extracto orgánico de recursos hídricos de la vereda Monterredondo (Antioquia), contaminados por el uso de pesticidas en la agricultura, en la producción porcina y avícola como un diagnóstico de su calidad para entender su influencia en estas fuentes de agua en el municipio de San Pedro de Los Milagros (Antioquia).

\section{MATERIALES Y MÉTODOS.}

Tipo de estudio. Investigación experimental cuantitativa en donde se evaluó la genotoxicidad de dos muestras de agua de fuentes hídricas sin tratar y una muestra de agua tratada de la Hacienda la Montaña de la Universidad de Antioquia, la cual se tomo como una estación importante dentro de la vereda.

Sitio de estudio. Estas fuentes hídricas suministran agua a la vereda Monterredondo ubicada a $3 \mathrm{~km}$ de la cabecera municipal de San Pedro de los Milagros (Antioquia) y a 41 kilómetros de Medellín, a una latitud norte: $6^{\circ} 27^{\prime} 41^{\prime \prime}$, longitud al oeste Greenwich: $75^{\circ}$ $33^{\prime} 31^{\prime \prime}$. Limita por el norte con Belmira y Entrerríos; por el sur con Bello, Copacabana y Girardota; por el oriente con: Donmatías y por el occidente con Sopetrán y San Jerónimo. Temperatura promedio de $15^{\circ} \mathrm{C}$ y una altura de 2.350 a 2.500 msnm. Según la apreciación del $100 \%$ de las familias de la vereda, al hacerles una encuesta domiciliaria y por observación de los investigadores durante la misma; las fuentes hídricas están contaminadas. Los residentes de la vereda expresaron que utilizan de manera indiscriminada plaguicidas y pesticidas tóxicos en las actividades agropecuarias y que algunos emplean el agua de estas fuentes para uso doméstico (Tabla 1 ).

Se utilizó el ensayo Cometa para determinar genotoxicidad de dos muestras de agua sin tratar, recogidas de las quebradas Fray Juana y El Hato, y una muestra de la planta de tratamiento de la Hacienda La Montaña de la Universidad de Antioquia, abastecida por la quebrada Fray Juana. Este método es útil para la valoración del biomonitoreo de daños genéticos (mutagenicidad y genotoxicidad).

Análisis de genotoxicidad. Fue efectuado por el grupo de investigación del Laboratorio de Agua de Mar de la Facultad de Medicina de la Universidad de Antioquia, el cual determinó la fragilidad osmótica de eritrocitos, la viabilidad celular y el daño en el ADN de linfocitos de células humanas expuestas a los tres EO de las muestras de agua a 4 y $37^{\circ} \mathrm{C}(11,12)$.

\section{Recolección y tratamiento de muestras.} Las muestras de agua recolectadas (tratada y no tratada) fue de $100 \mathrm{~L}$ de agua de cada una de las fuentes hídricas mencionadas, depositados en recipientes 
Tabla 1. Distribución porcentual de los productos químicos de uso más frecuente por las familias encuestadas en la vereda Montenegro del municipio de San Pedro de los Milagros, 2008.

\begin{tabular}{|c|c|c|c|}
\hline Producto & Toxicidad & Uso & Frecuencia* \\
\hline Límpidoß (Hipoclorito de sódio 6\%) & III Media & Desinfetante & $82 \%$ \\
\hline Lorsban $®$ (Clorpirifos) & I Alta & Plaguicida & $47 \%$ \\
\hline Urea ${ }^{\circledR}$ ( Nitrógeno) & IV Baja & Fertilizante de plantas & $34 \%$ \\
\hline Ráfaga $®$ (Clorpirifos) & I Alta & Plaguicida & $33 \%$ \\
\hline Látigo® (Clorpirifos) & I Alta & Plaguicida & $30 \%$ \\
\hline Manzate $®$ (Ditiocarbamato) & Mediana & Plaguicida & $27 \%$ \\
\hline Curagan $®$ (Fenol) & Alta acuática & Antiinfeccioso & $26 \%$ \\
\hline Calmafox $®$ (medicamento) & No aplica & Aporte de vitaminas & $25 \%$ \\
\hline Oxitetraciclina (medicamento) & Baja & Antiinfeccioso & $22 \%$ \\
\hline Triple quince $®(N, P, K)$ & No aplica & Fertilizante de plantas & $22 \%$ \\
\hline Vitaminas Complejo B & No aplica & Aporte de vitaminas & $19 \%$ \\
\hline Lutalise $®\left(P G F_{2}\right.$ alfa $)$ & No aplica & Estimular ovulación & $18 \%$ \\
\hline Neguvon $®$ (Metrifonato) & I Alta & Plaguicida & $16 \%$ \\
\hline Ganabaño $®$ (Cipermetrina) & Extrema Alta & Insecticida & $15 \%$ \\
\hline Triatox $®$ (Amitraz) & Media & Ectoparásitos & $14 \%$ \\
\hline Panacur $®$ (Fenbendazol ) & Baja & Nematicida & $12 \%$ \\
\hline Karate $®$ (D-Cyalotrina) & Baja & Plaguicida & $11 \%$ \\
\hline Barricada $®$ (Cipermetrina) & Baja & Plaguicida & $11 \%$ \\
\hline Engeo $®$ (Neonicotinoide+piretroide) & Baja & Plaguicida & $10 \%$ \\
\hline Furadán ${ }^{\circledR}$ (Carbofurán) & Extrema Alta & Plaguicida & $8 \%$ \\
\hline Tetraciclina & No aplica & Antibiótico & $8 \%$ \\
\hline Roundup $®$ (Glifosato) & Baja & Herbicida Total & $8 \%$ \\
\hline Vitamina Mk & No aplica & Aporte de vitaminas & $8 \%$ \\
\hline Lepecid $®$ (Clorpirifos) & III Mediana & Larvicida y antiséptico & $7 \%$ \\
\hline Piretroides & Baja & Insecticida & $7 \%$ \\
\hline Ivermectina Genfar $\AA$ & Extrema Alta & Ectoparásitos & $6 \%$ \\
\hline Pirestar ${ }^{\circledR}$ (Permetrina) & III & Plaguicida & $6 \%$ \\
\hline Oxitocina & No aplica & Hormonas & $6 \%$ \\
\hline Glifosato & Baja & Herbicida total & $4 \%$ \\
\hline
\end{tabular}

plásticos de polietileno de alta densidad (HDPE) y transportados por vía terrestre a temperatura ambiente hasta el Laboratorio de Bioquímica de la Facultad de Medicina de la Universidad de Antioquia para la determinación del efecto genotóxico.

\section{Tratamiento para las pruebas de genotoxicidad $y$ viabilidad}

Concentración del EO. Los 100 L de agua recogidos de cada una de las quebradas y de la planta de tratamiento se concentraron porque los compuestos genotóxicos pueden estar a muy bajas concentraciones. La adsorción del EO no volátil contenido en estas muestras de agua se hizo por el método de adsorción en resinas styrene divinylbenceno amberlita XAD-2 y XAD-
7 no polares. Cada muestra se pasó por una columna que contenía $100 \mathrm{~g}$ de resina XAD-2 y $100 \mathrm{~g}$ de XAD-7 a una velocidad aproximada de $15 \mathrm{~mL} / \mathrm{min}$. La elución se realizó con $300 \mathrm{~mL}$ de acetona. El volumen del eluyente se retiró por rota evaporación a baja presión hasta eliminar la acetona y la porción acuosa se liofilizó. Se pesaron los extractos liofilizados, se diluyeron en dimetilsulfóxido al $50 \%$ y se guardaron a $4^{\circ} \mathrm{C}$. Las células humanas se trataron con EO obtenido de las aguas recolectadas para establecer viabilidad y genotoxicidad.

Prueba de viabilidad del efecto citotóxico. Consiste en tomar una muestra de sangre de un donante sano, con su consentimiento informado y comprendido. La sangre total se trató con ácido 
dietilenodiaminotetracético y por el método de centrifugación en un gradiente de densidad de Ficoll, se aíslaron los linfocitos humanos. Luego, se evaluó la viabilidad por el método de exclusión del colorante azul tripano al $0.2 \%$ y se incubaron tres diluciones del EO de las muestras de agua a 4 y $37^{\circ} \mathrm{C}$ durante una hora. Acto seguido; se evaluó de nuevo la viabilidad de los linfocitos para establecer la concentración más alta de la muestra de agua en la cual no se presentó efecto citotóxico (13).

Prueba de genotoxicidad. Realizada para cada dilución del EO de las muestras de agua por duplicado para determinar el daño producido por éste al ADN de los linfocitos de sangre total, mediante la técnica de Single Cell Gel Electrofóresis (SCGE), conocida como ensayo cometa. Este análisis consiste en someter los EO de las tres muestras de agua recolectadas en función de la concentración por duplicado a pruebas de electroforesis en agarosa del ADN nuclear de células individuales durante 30 min a 25 voltios y $300 \mathrm{~mA}$ para estimar la fragmentación del DNA de las células de los linfocitos humanos, producida por los EO comparada con un control positivo, el $\mathrm{H}_{2} \mathrm{O}_{2}(100 \mu \mathrm{M})$ y el buffer fosfato salino (PBS) como control negativo para permitir el desenrollamiento del ADN y expresión de sitios lábiles a álcalis. Acto seguido, las láminas con el ADN de los linfocitos, se colorearon con $50 \mu \mathrm{l}$ de Bromuro de Etidio al $2 \%$ y después se examinaron en un microscopio de fluorescencia equipado con un filtro de excitación de 515-560 nm y un filtro barrera de $590 \mathrm{~nm}$, usando una magnificación de 40X (12).

Análisis de genotoxicidad. El análisis de genotoxicidad causado por cada una de las muestras de agua se efectúo al menos con 50 células del ADN nuclear por cada concentración del EO, utilizando un programa de computador de análisis de imágenes del ensayo de la longitud del cometa que permite recolectar datos midiendo la longitud de la migración y la intensidad de la fluorescencia como Momento de Olive (MO), suministrando la relación de la distancia entre el centro de gravedad de la cabeza del cometa $(\mathrm{CGH})$ al centro de gravedad de su cola (CGT) y el porcentaje de DNA de la cola, utilizando el software Comet Score, versión 1.5 que proporciona el porcentaje de DNA transformado (14).

Análisis estadístico de varianzas. El análisis estadístico de varianzas del promedio del logaritmo de la longitud del cometa con dos factores: la concentración del EO y el lugar de recolección de las muestras de agua con un nivel de significancia de $(p<0.05)$, se realizó con el paquete estadístico STATISTICA 7.0 (Stat Soft, Inc. Tulsa, OK, USA) (15).

\section{RESULTADOS}

Los resultados del efecto genotóxico de los EO de las muestras hídricas recolectadas en la vereda Monterredondo, sobre los linfocitos humanos, en función de la concentración, el sitio de recolección y la temperatura a 4 y $37^{\circ} \mathrm{C}$, mostraron significancia estadística. (Tablas 2 y 3 ).

El análisis de varianzas de las medias del efecto genotóxico de las concentraciones de 40,120 y $200 \mathrm{mg} / \mathrm{mL}$ de los EO sobre

Tabla 2. Valores promedio de la longitud del cometa de los linfocitos humanos incubados en función de la concentración de tres extractos orgánicos de agua de la vereda Monterredondo de San Pedro de los Milagros (Antioquia), Colombia, a $4^{\circ} \mathrm{C}$.

\begin{tabular}{|c|c|c|c|c|}
\hline $\begin{array}{l}\text { Sitio de la } \\
\text { Muestra* }\end{array}$ & $\begin{array}{c}\mathrm{C} * * \text { en } \\
\mathrm{mg} / \mathrm{I}\end{array}$ & $\begin{array}{l}\text { No de } \\
\text { Células }\end{array}$ & $\begin{array}{l}\text { Promedio de } \\
\text { Longitud del } \\
\text { Cometa } \mu \mathrm{m}\end{array}$ & St \\
\hline \multirow{3}{*}{$\begin{array}{l}\text { Quebrada Fray } \\
\text { Juana }\end{array}$} & 40 & 76 & 108.90 & 25.80 \\
\hline & 120 & 82 & 121.00 & 20.30 \\
\hline & 200 & 79 & 133.10 & 23.80 \\
\hline \multirow{3}{*}{$\begin{array}{lr}\text { Planta } & \text { de } \\
\text { tratamiento } \\
\text { Hacienda } \\
\text { Montaña }\end{array}$} & 40 & 78 & 127.90 & 2.20 \\
\hline & 120 & 81 & 119.60 & 26.00 \\
\hline & 200 & 79 & 128.50 & 32.80 \\
\hline \multirow{3}{*}{$\begin{array}{l}\text { Quebrada } \\
\text { Hato }\end{array}$} & 40 & 81 & 107.10 & 22.60 \\
\hline & 120 & 82 & 133.60 & 28.00 \\
\hline & 200 & 79 & 147.10 & 30.60 \\
\hline $\begin{array}{l}C \circ n \text { t } r \circ l^{\prime} \\
\text { negativo }\end{array}$ & 000 & 81 & 99.60 & 15.70 \\
\hline Control positivo & $\begin{array}{c}\mathrm{H}_{2} \mathrm{O}_{2} \\
100 \mu \mathrm{M}\end{array}$ & 67 & 119.40 & 31.70 \\
\hline
\end{tabular}

*Efecto del sitio: $\mathrm{F}=3.65, \mathrm{p}=0.02$; **Efecto de la concentración: $\mathrm{F}=67.3, \mathrm{p}<0.001$. Efecto de la interacción entre el sitio de recolección de la muestra frente a la concentración: $F=7.67$, $\mathrm{p}<0.001$. $\mathrm{C}=$ concentración. $\mathrm{St}=$ Desviación estándar. 
Tabla 3. Valores promedio de la longitud del cometa de los linfocitos humanos incubados en tres extractos orgánicos de agua de la vereda Monterredondo de San Pedro de los Milagros (Antioquia), Colombia, en función de la concentración, a $37^{\circ} \mathrm{C}$.

\begin{tabular}{|c|c|c|c|c|}
\hline $\begin{array}{l}\text { Sitio de la } \\
\text { Muestra* }\end{array}$ & $\begin{array}{l}\mathrm{C} * * \\
\mathrm{mg} / \mathrm{L}\end{array}$ & $\begin{array}{l}\text { No de } \\
\text { Células }\end{array}$ & $\begin{array}{l}\text { Promedio de } \\
\text { Longitud del } \\
\text { Cometa } \mu \mathrm{m}\end{array}$ & St \\
\hline \multirow{3}{*}{$\begin{array}{l}\text { Quebrada Fray } \\
\text { Juana }\end{array}$} & 40 & 84 & 111.4 & 21.8 \\
\hline & 120 & 79 & 130.4 & 23.0 \\
\hline & 200 & 84 & 139.6 & 21.2 \\
\hline \multirow{3}{*}{$\begin{array}{lr}\text { Planta } & \text { de } \\
\text { trata mi ent } \\
\text { Hacienda } \\
\text { Montaña }\end{array}$} & 40 & 72 & 119.3 & 23.6 \\
\hline & 120 & 52 & 179.6 & 34.7 \\
\hline & 200 & 57 & 181.6 & 24.7 \\
\hline \multirow{3}{*}{$\begin{array}{l}\text { Quebrada } \\
\text { Hato }\end{array}$} & 40 & 75 & 143.5 & 30.4 \\
\hline & 120 & 70 & 164.4 & 29.9 \\
\hline & 200 & 57 & 180.8 & 25.1 \\
\hline Control negativo & 000 & 79 & 109.9 & 21.6 \\
\hline Control positivo & $\begin{array}{c}\mathrm{H}_{2} \mathrm{O}_{2} \\
100 \mu \mathrm{M}\end{array}$ & 72 & 113.7 & 23.9 \\
\hline
\end{tabular}

*Efecto del sitio: $\mathrm{F}=86.96, \mathrm{p}<0.001$. **Efecto de la concentración: $\mathrm{F}=229.05, \mathrm{p}<0.001$. Efecto de la interacción del sitio de la muestra frente a la concentración: $F=22.48$, $p<0.001$. St: desviación estándar.

los linfocitos humanos expuestos por una hora a 4 y $37^{\circ} \mathrm{C}$, evidenció daño genotóxico significativo $(p<0.001)$, dependiente de la interacción entre la concentración, el sitio de recogida y la temperatura. (Figuras 1 y 2 ).

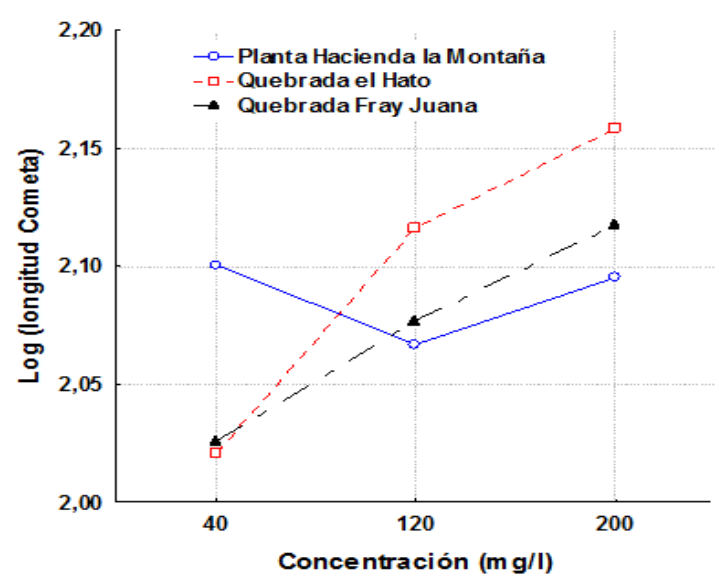

Figura 1. Análisis de varianzas de medias del logaritmo de la longitud del cometa de linfocitos humanos incubados en tres extractos orgánicos de agua de la vereda Monterredondo de San Pedro de los Milagros (Antioquia), Colombia, en función de la concentración, a $4^{\circ} \mathrm{C}$.

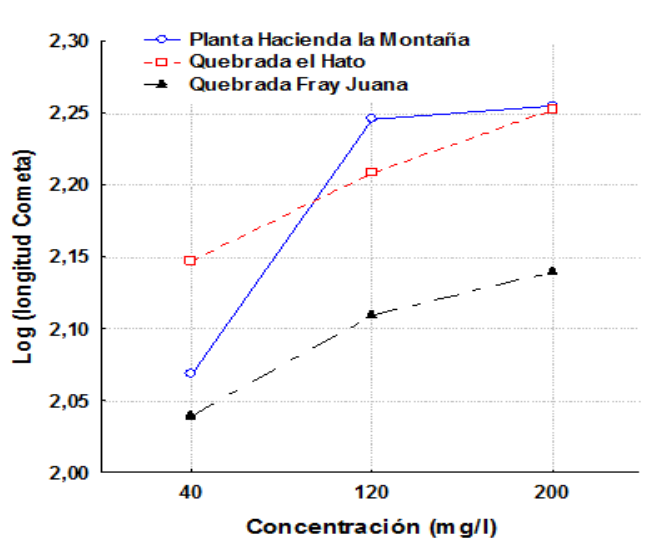

Figura 2. Análisis de varianzas de medias del logaritmo de la longitud del cometa de linfocitos humanos incubados en tres extractos orgánicos de agua de la vereda Monterredondo de San Pedro de los Milagros (Antioquia), Colombia, en función de la concentración, a $37^{\circ} \mathrm{C}$.

Las figuras 3 y 4 muestran el agua del sitio

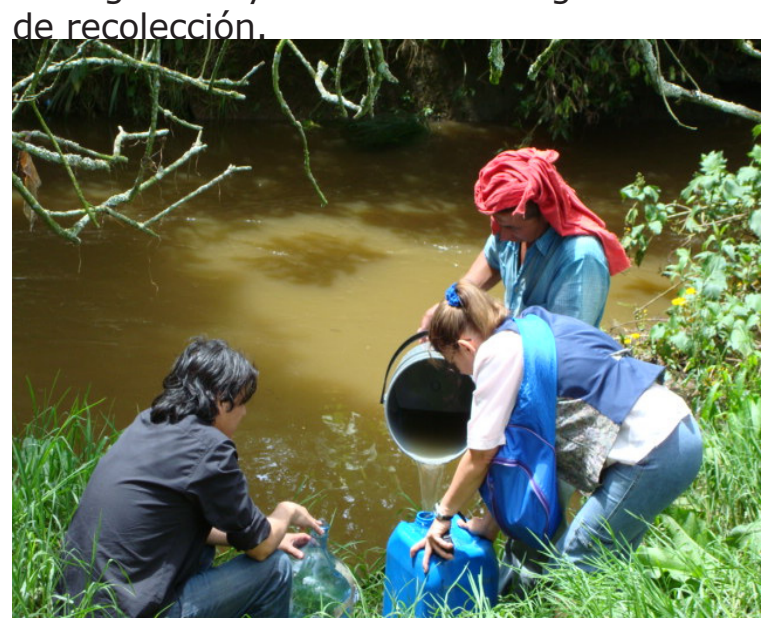

Figura 3. Toma de nuestras de la quebrada el Hato.

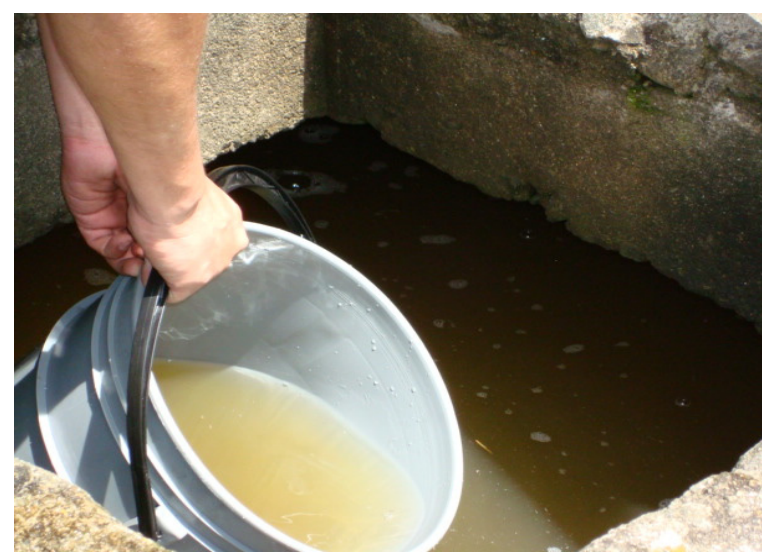

Figura 4. Toma de nuestras de la planta de tratamiento de la Hacienda La Montaña. 
Los resultados de esta investigación son un indicador del efecto genotóxico de esta agua; el mayor efecto de genotoxicidad y mutagenicidad se observó en los linfocitos humanos expuestos al EO de concentración de $200 \mathrm{mg} / \mathrm{mL}$ a $37^{\circ} \mathrm{C}$ por

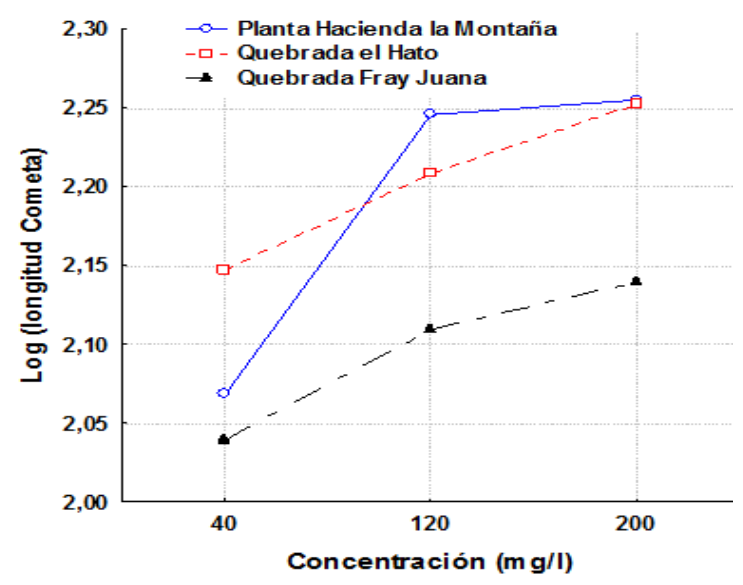

Figura 5. Electroforesis de linfocitos humanos incubados a $37^{\circ} \mathrm{C}$ en EO de agua de la vereda Monterredondo.

una hora (Figura 5).

Este análisis se aproxima a lo observado en ensayos in vitro y en poblaciones expuestas, reportados en la literatura, utilizando el ensayo cometa (15-18).

\section{DISCUSIÓN}

El análisis de los resultados obtenidos son indicadores de la genotoxicidad de los EO expuestos a células humanas a 4 y $37^{\circ} \mathrm{C}$ de las tres muestras estudiadas contaminadas por vertimientos. Ello posiblemente por la bioacumulación y biomagnificación de toxinas en el ecosistema como resultado de ésta actitud y práctica agropecuaria con plaguicidas, herbicidas y disposición inapropiadas de los residuos.

Los análisis de los valores de longitud del cometa de linfocitos humanos incubados en lostresEOdeaguadelavereda Monterredondo en función de la concentración de 40, 120 y $200 \mathrm{mg} / \mathrm{mL}$, expuestos por una hora a 4 y $37^{\circ} \mathrm{C}$; mostraron un efecto significativo $(p<0.001)$. Al igual que los análisis de las varianzas de los valores promedios de longitud del cometa que presentaron una interacción significativa $(p<0.001)$ entre los factores: sitio de recolección del agua y concentración de 40,120 y $200 \mathrm{mg} / \mathrm{mL}$ del EO de las muestras de agua a 4 y $37^{\circ} \mathrm{C}$. El análisis estadístico de estos datos permitió evidenciar las siguientes observaciones como resultado del efecto genotóxico directo de los EO de las tres muestras de agua de la vereda Monterredondo sobre linfocitos humanos de sangre total: 1) El efecto genotóxico es directamente proporcional a la concentración del EO, a mayor concentración $(200 \mathrm{mg} / \mathrm{mL})$, mayor probabilidad de genotoxicidad. 2) Se reveló que el EO de la muestra de agua de la quebrada el Hato presentó el mayor efecto genotóxico, resultado esperado, porque recoge aguas servidas muy contaminadas por plaguicidas, residuos de bovinos y porcinos. 3) La muestra de agua tomada de la planta de tratamiento de la Hacienda La Montaña, presentó una alta genotoxicidad relativa, comparada con la muestra de agua de la quebrada Fray Juana, cuya genotoxicidad, se observó particularmente a $37^{\circ} \mathrm{C}$.

El análisis de varianzas de medias del Momento de Olive de linfocitos humanos incubados en los EO de las muestras de agua estudiadas en función de la concentración y el sitio de recolección, a 4 y $37{ }^{\circ} \mathrm{C}$ (Figuras 1 y 4 ), confirma la hipótesis planteada y evidencia que los elementos tóxicos presentes en los efluentes derivados de vertimientos de las actividades agropecuarias, generan genotoxicidad y pueden estar incidiendo en la situación de salud pública de las comunidades que se sirven de estas aguas contaminadas. Las aguas utilizadas, provenientes de la producción porcícola, son vertidas a las quebradas de la vereda; siendo la principal receptora la quebrada El Hato. Esta actitud y práctica se relaciona con problemas ambientales bien conocidos a escala mundial, generados por la porcicultura, donde las excretas de los cerdos son contaminantes potenciales del agua superficial y del subsuelo por su alta concentración de gérmenes patógenos (bacterias, hongos, virus y parásitos), 
metales pesados (cobre y zinc) y materia orgánica con fósforo, potasio y nitrógeno, cuyos procesos biológicos y fisicoquímicos producen la formación de compuestos químicos y gases nocivos, como el dióxido de carbono $\left(\mathrm{CO}_{2}\right)$, el amoníaco $\left(\mathrm{NH}_{3}\right)$, el sulfuro de hidrógeno $\left(\mathrm{H}_{2} \mathrm{~S}\right)$ y el metano $\left(\mathrm{CH}_{4}\right)$ que afectan la salud humana y la de los porcinos, deteriorando los recursos naturales e incide negativamente en la calidad de vida. Esto puede estar relacionado con lo observado en algunas personas de la vereda durante las entrevistas, principalmente niños y adultos mayores, quienes expresaron alteraciones respiratorias, oftalmológicas y dermatológicas y la relacionaban con el contacto directo que tienen con el agua de uso doméstico (19-22).

El ensayo cometa a $37^{\circ} \mathrm{C}$ muestra la mayor fragmentación del $A D N$, porque a esta temperatura se presenta el daño genotóxico y simultáneamente un proceso de reparación, el cual implica fragmentación del ADN. Mientras que en el ensayo a $4^{\circ} \mathrm{C}$ no se presenta actividad de las enzimas del sistema de reparación. Por tanto, el resultado se explica únicamente por el daño genotóxico del EO y éste, se aproxima a los reportes de la literatura sobre genotoxicidad producida por plaguicidas y pesticidas (11, $13,15-17,23)$.

El efecto genotóxico sobre el ADN, genera errores en el proceso de su división celular (mitosis), lo que puede originar, replicación celular desordenada o mutaciones y el riesgo de generar algún tipo de cáncer (24). Desde esta perspectiva, el (los) agente (s) genotóxico (s) presente (s) en las fuentes hídricas y en el medioambiente de la vereda Monterredondo, reacciona ( $n$ ) químicamente con el ADN. Esta interacción tiene la posibilidad de ocasionar mutación de los códigos de la secuencia del ADN; pudiendo dañar su replicación mediante un enlace irreversible (covalente), alterando así, la unión de la(s) enzima(s) al material genético, involucradas en dicha replicación que origina efectos negativos sobre la salud, lo que puede ocurrir por una fotodegradación de los compuestos orgánicos presentes en el agua (23).
El análisis estadístico de los resultados de esta investigación da lugar a que todos los entes gubernamentales ambientales, la Universidad de Antioquia y la comunidad de la vereda sean conscientes sobre el riesgo potencial de la actitud y práctica del uso indiscriminado y sin control de estos xenobióticos y adopten medidas de contención del mismo. Considerando que es una problemática reconocida en la literatura; la cual reporta: 1) contaminación del medio ambiente por xenobióticos y de sus efectos negativos en la salud de los seres vivos. 2) alteración de los ecosistemas. 3) aumento de resistencia de las plagas a los plaguicidas. 4) intoxicaciones y muertes producidas por el uso y contacto de los seres vivos con el agua contaminada. 5) teratogénesis y mutagénesis en diversos seres vivos (24-27).

Asimismo, se necesita establecer medidas de mejoramiento de la gestión ambiental en esta región, una responsabilidad social de todos los involucrados; pero le concierne principalmente a las autoridades educativas y públicas competentes valorar y analizar el impacto riesgo/beneficio del uso de los plaguicidas y sus consecuencias, teniendo en cuenta todas las precauciones posibles para proteger el medio ambiente y la salud de la población, puntualizando decisiones sobre políticas públicas o ideológicas con un conocimiento científico más profundo y con mayor mesura para contribuir al mejoramiento de la calidad de vida de la región y del país. Esta situación requiere que se hagan los correctivos pertinentes para su impedimento en beneficio de la comunidad y el medio ambiente.

En conclusión, la comparación del efecto genotóxico de las muestra de agua de las tres fuentes hídricas en la concentración de $200 \mathrm{mg} / \mathrm{mL}$ del EO a 4 y $37^{\circ} \mathrm{C}$, permiten deducir que la muestra de agua de la quebrada el Hato (no tratada), presentó el mayor grado de genotoxicidad y el menor la muestra de agua de la quebrada Fray Juana (no tratada). La muestra de agua de la planta de tratamiento de la Hacienda la Montaña presentó una alta genotoxicidad relativa comparada con el grado de genotoxicidad de la muestra de 
agua de la quebrada Fray Juana. El mayor grado de genotoxicidad de la quebrada el Hato se correlaciona con lo observado, ya que recoge aguas servidas contaminadas con residuos avícola, porcícola, vacuno y de la agricultura. Se evidencia actitudes y prácticas en la vereda y en la Hacienda la Montaña, tales como la utilización inadecuadas de plaguicidas en las actividades agropecuarias y su vertimiento a las fuentes de agua de la vereda Monterredondo que repercute en su calidad, contribuyendo a incrementar la contaminación ambiental de la zona. También se reveló una exposición permanente de la comunidad a un riesgo para la salud por el uso inadecuado de plaguicidas. Esta investigación es un punto de partida para hacer otros estudios más profundos en torno a este aspecto de primordial interés global para conocer el impacto y la magnitud de los efectos de los elementos tóxicos presentes en el agua en los organismos vivos, que luego se convierten en alimento humano para la salud y el desarrollo del ámbito regional y nacional.

Esta investigación sugiere una gestión preventiva que abarque aspectos integrales, que van desde los recursos hídricos disponibles en la vereda hasta las actitudes y las prácticas de los pobladores. Por tanto se sugiere que la Universidad de Antioquia en forma intersectorial, en cumplimiento de su responsabilidad social y ambiental debe: 1) a corto plazo, efectuar labores de capacitación a trabajadores y empleados de la hacienda con respecto al manejo adecuado de las aguas servidas y los residuos sólidos. 2) a mediano y largo plazo, estructurar una política ambiental, coordinada y articulada con las autoridades administrativas locales y la autoridad ambiental regional (Corantioquia) para realizar evaluación, control y seguimiento de la problemática del recurso hídrico que genera problemas al medio ambiente y afecta la salud pública en la vereda Monterredondo. Asimismo, se debe evaluar la efectividad y la calidad del proceso de tratamiento del agua de la planta de la Hacienda La Montaña y hacer los correctivos necesarios con el propósito de garantizar la potabilidad del agua de uso y consumo en las actividades productivas y domesticas de la misma. Se sugiere también efectuar nuevas pruebas de genotoxicidad en células humanas y en las personas de la vereda para ayudar a mejorar su calidad de vida.

\section{Agradecimientos}

A Vicerrectoría de Extensión, Banco Proyectos -BUPPE-, por su financiación, a Lissette Marcela Jaramillo Díaz y Mary Luz Flórez Castaño, estudiantes en desarrollo de formación investigativa y a Wilmar Soler T., el apoyo ofrecido con su grupo de investigación de Agua de Mar.

\section{REFERENCIAS}

1. Cuenca P, Ramírez V. Aberraciones cromosómicas en trabajadoras expuestas a plaguicidas. Rev Biol Trop 2004; 52(3):623-628.

2. Agencia para Sustancias Tóxicas y el Registro de Enfermedades EU. Resumen de Salud Pública. Piretrinas y Piretroides 2003 septiembre (en línea). [Fecha de acceso 23 de julio de 2010]. URL disponible en: http://www.atsdr. cdc.gov/es/phs/es_phs155.html.
3. Castro R, Ramírez V, Cuenca P. Análisis de micronúcleos y otras anormalidades nucleares en el epitelio oral de mujeres expuestas ocupacionalmente a plaguicidas. Rev Biol Trop 2004; 52: 207-217.

4. Organización Panamericana de la Salud. Organización mundial de la Salud. Fichas técnicas de plaguicidas a prohibir o restringir, incluidos en el acuerdo No 9 de la XVI reunión del sector salud de Centroamérica y República Dominicana (RESSCAD). Costa rica: Organización Mundial de la Salud; 2001. 
5. Rivero O, Rizo P, Ponciano G, Olaiz G. Daños a la salud por plaguicidas. México: El Manual Moderno; 2001.

6. Yoke $\mathrm{CH}$. Inquietantes efectos del

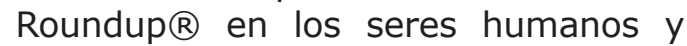
el ambiente. Red del Tercer Mundo 2005 (en línea). [Fecha de acceso 30 de junio de 2009]. URL disponible en: http://www.redtercermundo.org.uy/ texto_completo.php?id=2717.

7. Monroy CM, Cortés AC, Sicard DM, Groot H. Citotoxicidad y genotoxicidad en células humanas expuestas in vitro a glifosato. Biomédica 2005; 25:335-45.

8. Auditoría General de la República. Auditoría Analítica de Gestión al Uso y Manejo de Plaguicidas en Colombia. Bogotá D.C. 2004 (en línea). [Fecha de acceso 28 de diciembre 2008]. URL disponible en: http://www.auditoria. gov.co/9_documentos/2_3_2 plaguicidas.pdf.

9. La Red de Acción en Plaguicidas y sus Alternativas de América Latina (RAP$A L)$. Clasificación Toxicológica de los Plaguicidas 2004 (en línea). [Fecha de acceso 28 de diciembre 2008]. URL disponible en: http://www.rap-al.org/ index. php? seccion $=4 \& \mathrm{f}=$ toxicidad. . php.

10. Córdoba D. Toxicología, 5 ed. Bogotá DC: El Manual Moderno; 2006.

11. Meléndez I, Zuleta M, Marín I, Calle J, Salazar D. Actividad mutagénica de aguas de consumo humano antes y después de clorar en la planta de Villa Hermosa, Medellín. Iatreia 2001; 14(3):167-174.

12. Singh N, McCoy M, Tice R, Schneider E. A simple Technique for quantization of low levels of DNA damage in individual cells. Exp Cell Res 1988; 175(1):184-191.
13. Stahl R G. The genetic toxicology of organic compounds in natural waters and wastewaters. Ecotoxicol Environ Saf 1991; 22(1):94-125.

14. Comet Score. Version 1.5 Free comet scoring software (TriTek-Corp, USA) 2004 (en línea). [Fecha de acceso 17 de septiembre de 2007]. URL disponible en: http://autocomet.com.

15. Wayne D. Bioestadística. 3 ed. México DC: Limusa S.A.; 1993.

16. Zuleta $M$, Uribe $Y$, Valencia $C$, Vargas H, Orozco LY, López C. Contribución de la contaminación y cloración en la mutagenicidad, genotoxicidad y presencia de mutágenos en agua potable. Actualidades Biológicas 2004; 26(81): 125-136.

17. Henao B, Palacio JA, Camargo $M$. Evaluación genotóxica de los plaguicidas Cipermetrina y Diazinón en Tilapia Roja (Oreochromis sp.). Actualidades Biológica 2005; 27(82):43-55.

18. Soler W, Velásquez N, Soler J. Baja Genotoxicidad de extracto orgánico de agua de mar de Coveñas (Colombia). Vitae 2008; 15(1):96-102.

19. TaiganidesEP. PigWasteManagementand Recycling. The Singapore Experience. International Development Research Centre is a public corporation created by the Parliament of Canada in 1970, Ottawa (en línea): Fecha de acceso 17 de septiembre de 2009. URL Disponible en: http://idl-bnc.idrc.ca/dspace/ bitstream/10625/11104/1/91325.pdf.

20. Pérez R. Producción porcina $y$ contaminación del agua en la piedad, $\mathrm{MICH}$. Instituto de Investigaciones Económicas Universidad Nacional Autónoma de México. Fecha de acceso 25 de septiembre de 2010. URL Disponible en: http://www.bvsde. paho.org/bvsaidis/mexico13/159.pdf. 
21. Bove F, Shim Y, and Zeitz P. Drinking Water Contaminants and Adverse Pregnancy Outcomes. Environmental Health Perspectives supplement 2002; 110 (1):61-74. Fecha de acceso 25 de septiembre de 2010. URL Disponible en: http://www.ncbi.nlm.nih.gov/ pmc/articles/PMC1241148/pdf/ ehp110s-000061.pdf.

22. Velásquez N. Mutagenicidad y genotoxicidad de extractos de agua tratada para el consumo humano y de subproductos de la cloración. [Tesis de pregrado]. Medellín, Colombia: Universidad de Antioquia; 2000.

23. Yuan J, Liu $H$, Zhou LH, Zou YL, Lu WQ. Oxidative stress and DNA damage induced by a drinking-water chlorination disinfection by product 3-chloro-4-(dichloromethyl)-5hydroxy-2 $(5 \mathrm{H})$-furanone $(\mathrm{MX})$ in mice. Mutat Res 2006; 609 (2):129-136.

24. Restrepo G, Restrepo F. Fotodegradación de los compuestos orgánicos presentes en el agua de la quebrada la Fray Juana en la hacienda La Montaña, San Pedro de los Milagros, Antioquia (Colombia). [Tesis de pregrado]. Medellín, Colombia: Universidad de Antioquia; 2002.
25. Vindas R, Ortiz F. Genotoxicidad de tres plaguicidas utilizados en la actividad bananera en Costa Rica. Rev Biol Trop 2004; 52(3):601-609.

26. Aleem A, Malik A. Genotoxicity of water extracts from the River Yamuna at Mathura. Environ toxicol 2003; 18(2):69-77.

26. Contreras J, Astorga E, Castro R, Yentzen G, Cunsille M. Abortos espontáneos en hospital de Hay-Hay y su relación con labores agrícolas de la madre. Rev Chil Salud Pública 2005; 9(1):7-11.

27. Wu JY. Assessing surface water quality of the Yangtze Estuary with genotoxicity data. Pollut Bull 2005; 50(12): 1661-1667. 